\title{
Perencanaan Taman Islam pada Lansekap Islamic Center Provinsi NTB
}

\author{
MOHAMMAD BIRRUL WALIDAEN¹, NI WAYAN FEBRIANA UTAMI1*, \\ LURY SEVITA YUSIANA ${ }^{1}$
}

1. Program Studi Arsitektur Pertamanan, Fakultas Pertanian, Universitas Udayana, Denpasar, 80114, Indonesia

*E-mail: wayan_febriana@unud.ac.id

\section{ABSTRACT \\ Islamic Garden Planning at West Nusa Tenggara (NTB) Islamic Center}

West Nusa Tenggara (NTB) is one of province in Indonesia with majority of Muslim population. In consequence, it required to provide facility such as Islamic center. NTB Islamic Center was built as a center of Islamic studies and support the halal tourism in NTB. Currently, NTB Islamic Center is under construction and the landscape need to be planned in order to complete the overall construction. The aims of this study were to identify character of the landscape, to analyze any potential and obstruction at the site, and to plan the landscape of NTB Islamic Center with the Islamic garden concept. The method used in this research were literature study and field survey. Literature study was applied to get the formulation of the Islamic garden concept from Al-Qur'an and Hadith and the other literature related to Islamic garden. Furthermore, field survey was applied to determine some obstacles and the potentials of the site to support the NTB Islamic Center planning. The synthesis of study was applied as a concept to develop NTB Islamic Center. The concept of Islamic gardens was selected as a model of beauty of paradise as described in the Al-Qur'an and Hadith. Some adjustment were implemented in the site to conform its character and condition. The final result of this research was NTB Islamic Center site plan with emphasized on Islamic religion and culture.

Keywords: Islamic garden, Islamic center, landscape planning, West Nusa Tenggara (NTB)

\section{Latar Belakang}

Pusat kajian Islam atau yang lebih dikenal dengan Islamic Center awal mula berkembang di negara-negara barat, yaitu suatu tempat untuk menampung kegiatan shalat, ceramah agama atau kegiatan-kegiatan yang berhubungan dengan ke-Islaman (Karim, 2013). Sejalan dengan hal tersebut Direktorat Jenderal Bimbingan Masyarakat Islam Departemen Agama R.I tahun 1976, menerangkan Islamic Center merupakan lembaga keagamaan yang berfungsi sebagai pusat pembinaan dan pengembangan 
Agama Islam, serta berperan sebagai mimbar Pelaksanaan Da'wah dalam era pembangunan.

Nusa Tenggara Barat (NTB) merupakan sebuah Provinsi dengan mayoritas penduduk muslim yang berada di wilayah Indonesia bagian tengah. Data BPS tahun 2015 menunjukkan jumlah penduduk beragama Islam di NTB mencapai 4.599.892 jiwa $(96,11 \%)$, dengan total keseluruhan masyarakat NTB sejumlah 4.785 .980 jiwa. Provinsi NTB dengan mayoritas penduduk adalah beragama Islam sudah sepatutnya untuk memiliki sebuah Pusat Kajian Islam.

Islamic Center NTB seluas 6,7 hektar berada di pusat Kota Mataram. Dibangun dan direncanakan sebagai pusat kajian Islam serta sebagai penunjang Pariwisata Halal di daerah NTB (Pemprov NTB, 2016). Saat ini Islamic Center NTB terdiri dari Masjid dan Sekolah Islam. Pembangunan Islamic Center NTB dimulai dari tahun 2010 dan saat ini masih dilanjutkan dengan penyelesaian bagian luar bangunan Masjid.

Pariwisata halal yang identik dengan nuansa Islami menjadi dasar pertimbangan untuk menerapkan konsep Taman Islam pada perencanaan lansekap Islamic Center NTB. Taman Islam adalah suatu bentukan taman yang banyak diinspirasikan oleh penggambaran surga dalam ayat-ayat Al-Quran dan hadits-hadits Nabi Muhammad SAW. Rumusan masalah yang diangkat adalah bagaimana merencanakan lansekap Islamic Center NTB yang mendukung pembangunan kawasan Islamic Center NTB secara keseluruhan. Sedangkan tujuan yang ingin dicapai dalam penelitian ini adalah untuk membuat perencanaan pengembangan lansekap Islamic Center NTB dengan menerapkan konsep Taman Islam.

\section{Metode Penelitian}

\subsection{Tempat dan Waktu Penelitian}

Penelitian ini dilaksanakan di Kawasan Islamic Center NTB, yang berlokasi di Jalan Udayana No. 1 Kota Mataram, Provinsi NTB. Waktu penelitian dilakukan pada bulan Oktober tahun 2016 sampai dengan bulan Januari 2017.

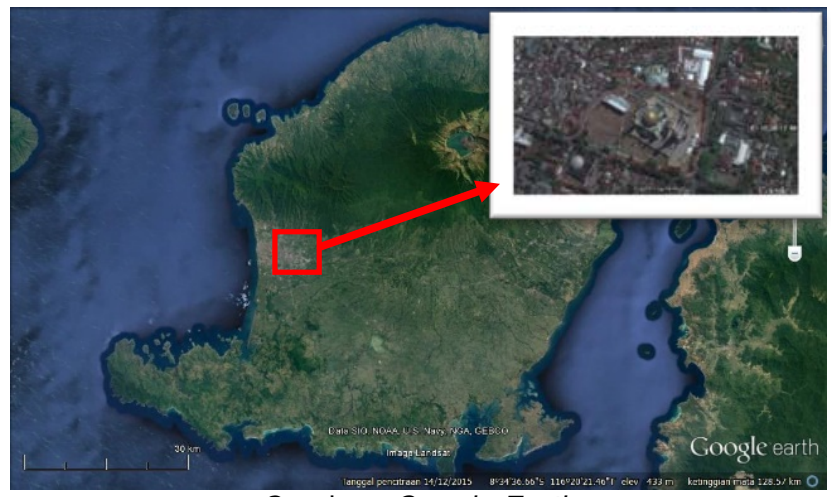

Sumber: Google Earth

Gambar 1. Peta lokasi Islamic Center NTB 


\subsection{Alat Penelitian}

Alat yang digunakan dalam penelitian ini meliputi kamera digital, meteran, HP Android dengan aplikasi Sound Meter (TM) Smart Tools co, serta perangkat komputer dengan software Auto Cad 2010, Google SketchUp 2015 dan Adobe Photoshop CS5.

\subsection{Metode Penelitian}

Penelitian ini dilakukan dalam dua tahap, yaitu tahap studi literatur dan tahap studi lapang. Tahap studi literatur dengan analisis data sekunder (Chadwick, 1984) terhadap AlQuran dan Hadith serta literatur lainnya terkait Taman Islam untuk menghasilkan rumusan konsep dasar Taman Islam. Tahap studi lapang yang dilakukan berdasarkan proses berfikir lengkap merencana dan melaksanakan (Rachman, 1984) terdiri dari inventarisasi, analisis, sintesis, penetapan konsep hingga menghasilkan sebuah produk perencanaan berupa Site Plan.

\section{Hasil dan Pembahasan}

\subsection{Inventarisasi Tapak}

\subsubsection{Aspek Biofisik}

Islamic Center NTB adalah sebuah pusat kajian Islam yang sedang dibangun di pusat Kota Mataram, berlokasi di Jalan Udayana Nomor 1 Kota Mataram, Provinsi NTB. Kawasan seluas 6,7 hektar tersebut terdiri dari Masjid, Sekolah Islam, Museum, dan area komersial. Tapak memiliki letak yang strategis, berada di jalur arteri yang dapat dicapai menggunakan kendaraan umum maupun kendaraan pribadi.

Topografi di dalam tapak cenderung datar karena telah dilakukan persiapan lahan dan pengurugan tanah untuk meratakan lahan sekaligus penambahan top soil sebagai persiapan untuk penanaman vegetasi. Kondisi iklim mikro di tapak secara umum terasa panas terutama pada siang hari dengan suhu rata-rata 22,5 ${ }^{\circ} \mathrm{C}$ (BPS. 2015), kondisi tersebut disebabkan oleh kurangnya vegetasi peneduh di sekitar tapak. Sumber air di dalam tapak berasal dari air hujan dan sumur artesis.

Vegetasi eksisting yang berada di dalam tapak adalah pohon mangga (Mangifera indica L.), pohon jambu (Syzygium aqueum), pohon palem raja (Roystonea regia), pohon ketapang (Terminalia cattapa), dan pohon kurma (Phoenix dactylifera L.). Belum ada potensi pemandangan bagus ke segala arah karena kawasan Islamic Center Provinsi NTB dikelilingi oleh gedung sekolah, gedung perkantoran, dan pemukiman warga. Akustik atau bunyi-bunyian yang ada pada tapak didominasi oleh suara bising kendaraan bermotor yang melintasi Jalan Udayana dan Jalan Langko yang merupakan jalur arteri.

\subsubsection{Aspek Sosial dan Ekonomi}

Islamic Center NTB merupakan pusat kajian Islam yang nantinya akan dijadikan sebagai salah satu Destinasi Wisata yang menyajikan aktivitas wisata religi dan wisata edukasi. Kawasan tersebut juga termasuk salah satu bagian dari Kawasan Strategis Pariwisata Daerah (KSPD) untuk Kota Mataram dan sekitarnya (Bappeda NTB, 2013). Sumber dana proyek Pembangunan Kawasan Islamic Center NTB berasal dari APBD, dana tanggung jawab sosial (CSR) dari PT. Newmont Nusa tenggara serta dana bantuan yang digalang dari seluruh maryarakat Provinsi NTB. 


\subsection{Analisis dan Sintesis Tapak \\ 3.2.1 Aspek Biofisik}

Islamic Center NTB memiliki area terbuka yang cukup luas sekitar $43.550 \mathrm{~m}^{2}$ (63\% dari total kawasan) dapat dimanfaatkan sebagai ruang terbuka hijau. Kawasan yang terbangun seluas $23.649 \mathrm{~m}^{2}$ (35\%) terdiri dari Masjid, Sekolah, Museum, dan Area Komersial. Pembagian ruang tapak sesuai dengan aktivitas dan fungsi masing-masing ruang. Sekolah dan museum sebagai tempat berlangsungnya pendidikan dikelompokkan ke dalam Zona Pendidikan, Masjid sebagai tempat ibadah masuk dalam Zona Religi, dan Area Komersial masuk ke dalam zona rekreasi.

Tapak mengalami gangguan oleh suara bising kendaraan bermotor yang melintasi jalur arteri, sehingga perlu dilakukan peredaman terhadap kebisingan tersebut dengan menanam vegetasi peredam kebisingan pada bagian tapak yang dilalui oleh jalur arteri tersebut. Untuk mengganti bunyi bising kendaraan yang telah diredam oleh vegetasi peredam suara, maka bunyi yang akan dihadirkan dalam tapak adalah bunyi dari air seperti air mancur. Pada bagian tapak yang berbatasan langsung dengan pemukiman perlu dibangun tembok pembatas dan penanaman vegetasi untuk screening visual. Jenis tanaman yang berfungsi sebagai peredam suara dan screening pemandangan diantaranya glodogan tiang, teh-tehan dan pucuk merah.

Kondisi kesuburan tanah baik, kondisi tersebut sebagai potensi karena dapat ditanami berbagai jenis vegetasi. Kondisi tapak yang datar justru menjadi kendala. Kondisi tersebut dapat mengakibatkan pemandangan yang monoton, hal tersebut dapat ditangani dengan menghadirkan view menarik disekitar tapak. Dengan suhu udara rata-rata 27,05 ${ }^{\circ} \mathrm{C}$ dan kelembaban rata-rata 82,8 \%. Maka akan didapat nilai THI sebesar 26,07. Nilai THI tersebut berada pada kisaran nyaman, akan tetapi pada siang hari di tapak terasa panas karena mendapat sinar matahari secara langsung. Penambahan vegetasi peneduh dapat mengurangi efek panas dari radiasi matahari dan menambah kenyamanan pada tapak.

Kawasan Islamic Center NTB dapat dicapai menggunakan kendaraan pribadi maupun transportasi umum, sehingga perlu dibangun Halte untuk transportasi umum pada kawasan Islamic Center NTB. Transportasi tradisional seperti becak atau cidomo juga dapat mencapai kawasan tersebut melalui Jalan Aneka Raya di sebelah barat tapak. Pangkalan Cidomo juga menjadi sebuah fasilitas yang harus disediakan pada kawasan tersebut.

Sirkulasi dalam tapak Islamic Center NTB ini akan terbagi menjadi dua sirkulasi utama, yaitu sirkulasi kendaraan dan sirkulasi pejalan kaki. Kawasan tersebut dilalui oleh jalur arteri yang padat lalu lintas. Oleh sebab itu, sirkulasi kendaraan keluar masuk tapak harus diatur agar tidak mengganggu jalannya lalu lintas pada jalur arteri tersebut. Pengaturan dilakukan dengan menempatkan pintu keluar dan pintu masuk disetiap zona, serta sirkulasi dalam tapak juga harus diatur sebaik mungkin dengan menerapkan sistem pencapaian memutar (Hakim, 1987) untuk memperpanjang jarak tempuh, sehingga tidak terjadi perlawanan arah yang dapat memicu masalah pada jalannya sirkulasi.

Perkerasan di dalam tapak ini sebaiknya dikombinasikan dengan perkerasan berpori untuk memberikan kesempatan terjadinya penyerapan air ke dalam tanah yang 
lebih baik dibandingkan jika hanya menggunakan paving block biasa dan jalan aspal. Perkerasan berpori berupa paving cellular grid sebaiknya dipasang pada parkiran kendaraan untuk membantu penyerapan air serta menambah penghijauan.

Vegetasi eksisting yang akan dipertahankan pada tapak adalah Pohon Kurma (Phoenix dactylifera L.). Burung Merpati sering terlihat hinggap di atas menara dan kubah masjid. Untuk menambah jenis burung yang hadir di kawasan tersebut, maka perlu menciptakan habitat bagi burung-burung tersebut dengan menanam vegetasi yang sesuai dengan habitat burung tersebut. Bebrapa jenis vegetasi yang dapat dijadikan sebagai habitat burung diantaranya ketapang, Palem Raja, Bougenvil, dadap merah dan Sawo. Kebisingan pada tapak mencapai $68 \mathrm{~dB}$, untuk meredam kebisingan tersebut ditanam vegetasi multi strata sebagai peredam suara. Aspek visual pada tapak untuk saat ini belum memiliki nilai keindahan yang berpotensi untuk dipertahankan atau ditonjolkan, sehingga view akan difokuskan ke dalam tapak.

\subsubsection{Aspek Sosial dan Ekonomi}

Kawasan Islamic Center NTB akan dijadikan sebagai salah satu Destinasi Wisata Halal yang menyajikan aktivitas wisata religi dan wisata edukasi. NTB telah mengeluargan Peraturan Daerah nomor 2 tahun 2016 tentang Pariwisata Halal, sehingga dalam pengembangannya Islamic Center NTB harus berpedoman pada peraturan tersebut. Sehingga Islamic Center NTB Sebagai salah satu destinasi wisata halal harus menyediakan fasilitas yang layak untuk menunjang pariwisata halal. Salah satu contohnya adalah Fasilitas umum seperti kolam renang untuk laki-laki dan wanita yang berada pada area komersial harus terpisah.

Sebagai sebuah destinasi wisata, Islamic Center NTB akan ramai dikunjungi oleh banyak wisatawan. Terlebih ketika ada acara-acara besar yang diselenggarakan pada kawasan tersebut akan mengundang banyak pengunjung terutama masyarakat lokal. Kondisi tersebut tentunya akan dimanfaatkan oleh para pedagang pedagang kaki lima. Maka dari itu, harus disediakan tempat untuk para pedagang tersebut. Tempat yang akan disediakan berada di dekat kantin yang telah direncanakan pada area komersial.

\subsection{Konsep Dasar}

Konsep dasar perencanaan lansekap Islamic Center NTB adalah religus dan budaya. Konsep tersebut sesuai dengan lingkup kegiatan Islamic Center yang dikelompokkan menjadi kegiatan ubudiyah/ibadah pokok sebagai penerapan konsep religius dan kegiatan muamalah/kegiatan kemasyarakatan sebagai penerapan konsep budaya (Departemen Agama R.I, 1976). Religius atau suatu hal yang bersifat keagamaan, konsep religius tersebut didasari oleh aktivitas utama dalam Islamic Center NTB ialah aktivitas peribadatan dan pendidikan agama Islam. Sedangkan konsep budaya adalah budaya keislaman dari masyarakat NTB.

Islam selalu mendorong perkembangan kebudayaan dan kesenian setempat dalam perluasan ajarannya, sepanjang itu tidak bertentangan dengan Al-Qur'an dan As-Sunnah. Islam memberi kebebasan untuk mengembangkan seni dan berkarya (Fireza, 2007). Islamic Center NTB akan menjadi wadah untuk pelestarian budaya masyarakat Islam di 
NTB seperti penyiaran agama islam melalui kesenian, perekonomian syari'ah dan pariwisata halal, serta upacara keagamaan untuk peringatan hari besar Islam.

\subsection{Pengembangan Konsep}

Religius menurut umat Islam adalah melaksanakan ajaran agama secara menyeluruh. Menurut Muhaimin (2001) terdapat lima macam dimensi religius yang selanjutnya akan menjadi pertimbangan dalam menetapkan pengembangan konsep yang sesuai dengan konsep dasar diantaranya dimensi keyakinan, dimensi praktik agama, dimensi pengalaman, dimensi pengetahuan agama, dan dimensi pengalaman atau konsekuensi. Konsep pengembangan terdiri dari Rencana Tata Ruang, Rencana Sirkulasi, dan Rencana Tata Hijau.

\subsubsection{Rencana Tata Ruang}

Kawasan Islamic Center seluas 6,7 hektar, terdiri dari Masjid, Sekolah Islam, Museum, dan area komersial. Pembagian ruang pada tapak dilakukan berdasarkan fungsi yang telah direncanakan sejak awal. Secara umum lanskap Islamic Center Provinsi NTB dibagi menjadi tiga zona diantaranya zona pendidikan (penerapan dimensi pengetahuan agama) seluas $24.150 \mathrm{~m}^{2}$ (35\%), zona religi (penerapan dimensi praktik agama) $31.047 \mathrm{~m}^{2}$ (47\%), dan zona rekreasi (penerapan dimensi pengalaman atau konsekuensi) $12.216 \mathrm{~m}^{2}$ (18\%) (Gambar 2).

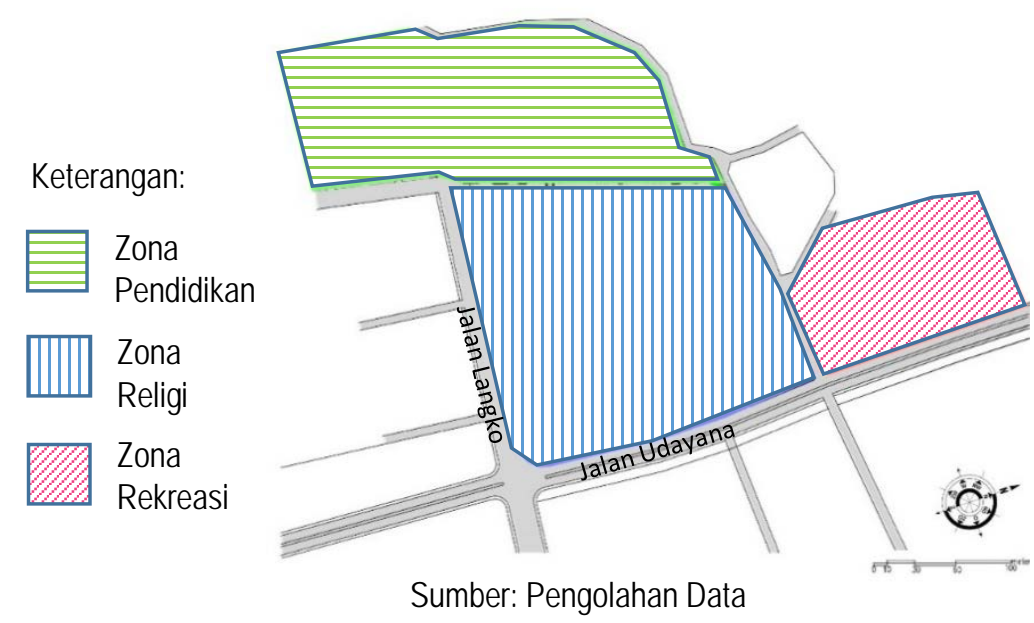

Gambar 2. Rencana Tata Ruang

\subsubsection{Rencana Sirkulasi}

Secara umum pola sirkulasi pada tapak didesain sedapat mungkin mengikuti aksis yang memudahkan orientasi terhadap arah kiblat yang berpatokan pada bangunan masjid. Sedangkan sirkulasi yang lainnya menyesuaikan dengan kondisi jalan raya diseputaran tapak. Sirkulasi dibedakan menjadi sirkulasi manusia dan sirkulasi kendaraan. (Gambar 3). Perencanaan sirkulasi ini bertujuan untuk mengatur arus kendaraan sekaligus menuntun pengguna untuk mengelilingi dan mengenali taman Islam tersebut (penerapan dimensi pengalaman). 


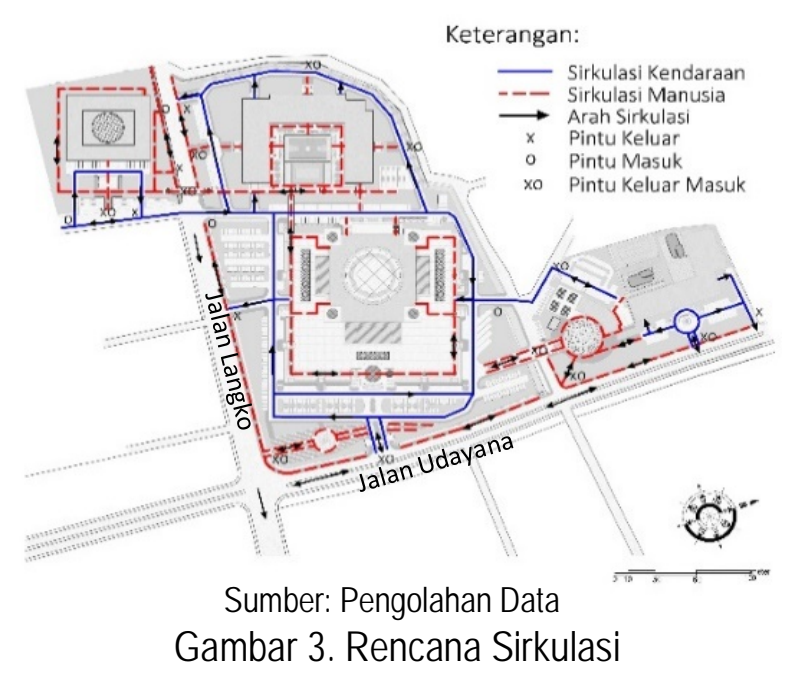

\subsubsection{Rencana Tata Hijau}

Tata hijau akan sangat berperan dalam memberikan kenyamanan pada Taman Islam agar pengguna nyaman melakukan ibadah serta menyajikan keindahan taman Islam sebagai gambaran dari surga. Penggunaan vegetasi dalam tapak dapat memberikan keseimbangan alam serta menjaga kelestarian lingkungan. Pemilihan jenis vegetasi dan peletakannya harus disesuaikan dengan tujuan perencanaan dan fungsi dari tanaman itu sendiri. Selain itu, tanaman yang dipilih juga harus memenuhi karakteristik taman Islam dimana tanaman yang digunakan tidak berpotensi membahayakan pengguna tapak. Jenis tata hijau pada tapak dikelompokkan berdasarkan fungsinya, diantaranya adalah tata hijau estetik, tata hijau penyangga, dan tata hijau pencipta iklim mikro (Gambar 4).

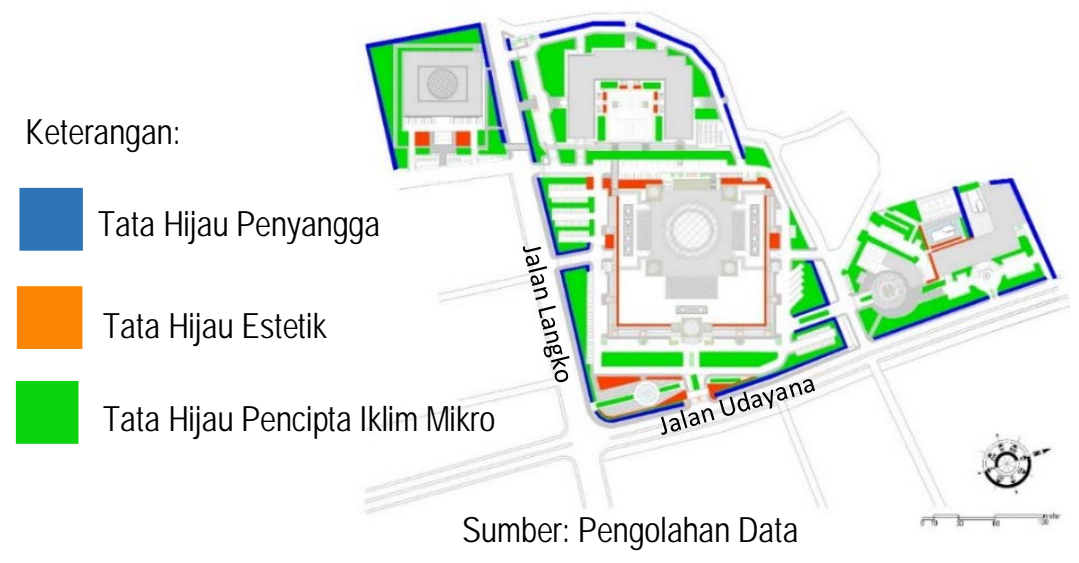

Gambar 4. Rencana Tata Hijau

\subsection{Perencanaan}

Konsep tata ruang, sirkulasi, dan tata hijau yang telah dijabarkan, selanjutnya akan digambarkan dalam bentuk site plan (Gambar 5). Dari site plan tersebut dapat dilihat karakteristik khusus Taman Islam yang diterapkan pada Lanskap Islamic Center NTB, yang meliputi: 
1. Adanya elemen air di dalam tapak berupa kran-kran air sebagai sarana berwudu yang terpisah antara laki-laki dan perempuan; kolam renang pada area komersial yang terpisah antara laki-laki dan perempuan; serta air mancur yang terdapat pada halaman depan masjid yang berfungsi sebagai focal point.

2. Pola perkerasan dengan pola simetris yang disesuaikan dengan kondisi tapak. Pembagian ruang pada kawasan Islamic Center NTB berdasarkan aktivitas diantaranya zona religi, zona pendidikan, dan zona rekreasi.

3. Sirkulasi yang diterapkan adalah pola sirkulasi terkontrol (controlled) yang terkesan lebih tegas dan formal. Penjelasan dari ayat al-quran mengenai jalan yang lurus juga mendukung untuk pemilihan pola controlled yang terkesan formal dan teratur.

4. Pemberian pilihan atau alternatif kepada para pengguna taman dilakukan dengan menyediakan berbagai jenis vegetasi, kran-kran air untuk berwudhu dalam jumlah yang mencukupi, beberapa paviliun diantara koridor sebagai tempat untuk berkontemplasi, serta adanya akses keluar masuk dari berbagai arah. Secara umum, Islamic Center menawarkan alternatif kegiatan wisata yaitu wisata religi dan wisata edukasi.

5. Unsur warna dan aroma ditampilkan pada tapak dengan penanaman tanaman dalam golongan tata hijau estetik yang menghasilkan aroma tertentu ataupun yang memiliki keragaman warna.

6. Pemilihan kelompok pohon peneduh yang tidak rimbun dan tertutup, serta penanaman beberapa vegetasi yang dapat memberikan hasil produksi berupa buah-buahan.

7. Taman Islam berfungsi sebagai ruang terbuka, sehingga akses keluar masuk disediakan dari berbagai arah. Setiap zona juga menyediakan akses yang terbuka bagi pejalan kaki dan pengendara kendaraan bermotor untuk memasuki kawasan.

8. Mempertahankan Cidomo alternatif transportasi tradisional untuk berwisata mengelilingi kawasan Islamic Center NTB dan sekitarnya.

9. Taman Islam memperhatikan keselamatan dengan menghindari elemenelemen taman yang dapat melukai atau membahayakan keamanan pengguna tapak. Misalnya menghindari penggunaan vegetasi yang berduri karena membahayakan pengguna.

10. Taman Islam yang menjunjung sifat kepatutan (sesuai dengan norma dan ajaran agama), hal-hal yang menyimpang dari ajaran Islam dan hal-hal yang menyebabkan dampak buruk sedapat mungkin dihindarkan. Taman yang bersifat terbuka dengan tidak menanam vegetasi yang rimbun dan tertutup akan memudahkan melakukan pengawasan antar sesama umat untuk menghindari hal-hal yang bersifat negatif. 


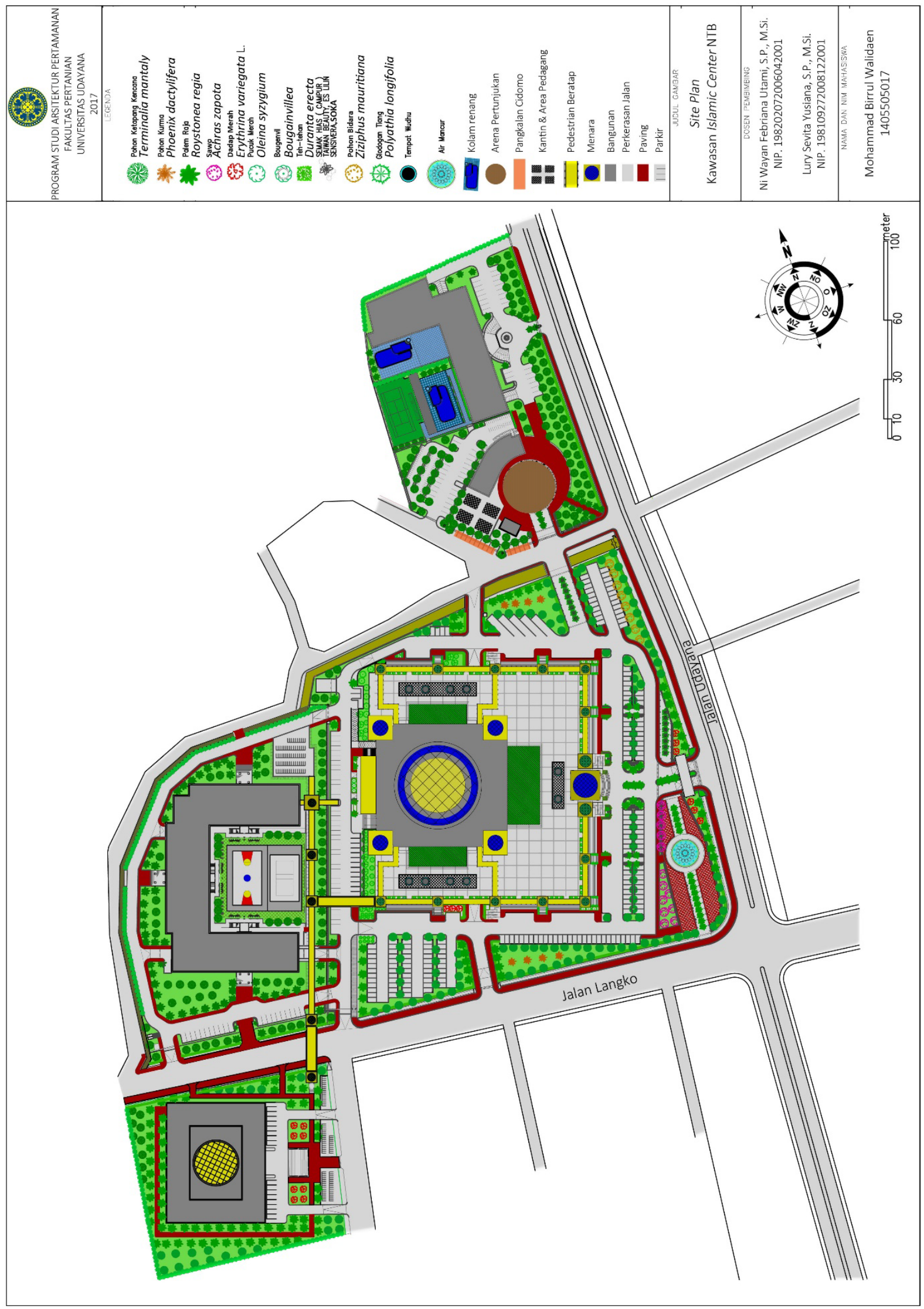

Gambar 5. Site Plan Taman Islam Islamic Center NTB 


\section{Simpulan dan Saran}

\subsection{Simpulan}

Konsep dasar perencanaan lansekap Islamic Center NTB adalah religus dan budaya. Konsep pengembangan terdiri dari Rencana Tata Ruang, Rencana Sirkulasi, dan Rencana Tata Hijau. Karakteristik khusus taman Islam yang dimunculkan pada perencanaan lanskap Islamic Center NTB adalah adanya elemen air di dalam tapak, pembagian ruang berdasarkan aktivitas yang direncanakan, pola sirkulasi formal dengan sistem pencapaian memutar, pemberian pilihan atau alternatif untuk pengguna taman, adanya unsur warna dan aroma yang ditampilkan, adanya pohon peneduh dan beberapa vegetasi produksi, menyediakan alternatif transportasi tradisional, memperhatikan keselamatan pengguna serta menunjang sifat kepatutan yang menjadi ciri khas taman Islam.

\subsection{Saran}

Hasil perencanaan lanskap Islamic Center NTB ini diharapkan dapat menjadi bahan masukan pengelola (Pemerintah Provinsi NTB) untuk diimplementasikan. Selain itu dapat dilaksanakan dan dikelola dengan baik sehingga tercipta suatu lanskap yang indah, sejuk, teduh, aman, terbuka, beragam, seimbang, nyaman dan menyenangkan bagi penggunanya, sebagaimana tujuan dari konsep taman Islam tersebut.

\section{Daftar Pustaka}

Bappeda NTB. 2013. Rencana Kawasan Strategis Pariwisata Daerah Provinsi NTB. Mataram.

BPS Provinsi NTB. 2015. Provinsi NTB dalam Angka Tahun 2015. Badan Pusat Statistik Provinsi NTB. Mataram.

Chadwick, B.A., H.M. Bahi dan S.L. Albrecht. 1984. Metode Pengetahuan IImu Pengetahuan Sosial (Terjemahan). University Bringham Young. USA.

Departemen Agama R.I, Direktorat Jenderal Bimbingan Masyarakat Islam. 1976. Petunjuk Pelaksanaan Proyek Islamic Center. Jakarta.

Fireza, Doni. 2007. Desain Taman Islami. Hikmah (PT. Mizan Publika), Jakarta.

Hakim, R. 1987. Unsur Perancangan dalam Arsitektur Lansekap. PT. Bumi Aksara. Jakarta.

Karim, A. 2013. Islamic Finance: The New Regulatory Challenge. Wiley. Singapore.

Muhaimin. 2001. Paradigma Pendidikan Islam. Rosdakarya. Bandung

Pemprov NTB. 2016. Peraturan Daerah tentang Pariwisata Halal. Mataram.

Rahman, Z. 1984. Proses Berpikir Lengkap Merencana dan Melaksana dalam Arsitektur Lanskap. Makalah Diskusi Festa VI Himagron. Bogor. 